\title{
Development of Assessment Instruments Based on High- Level Thinking Skills in the Receptive Language Skills Course for Unimed Indonesian Language and Literature Education Students
}

\author{
Atika Sadariah Nasution ${ }^{1, *}$ Wisman Hadi $^{2}$ Evi Eviyanti ${ }^{3}$ \\ ${ }^{1,2,3}$ Indonesian Language and Literature Education Study, Program of Postgraduate, Universitas Negeri Medan, \\ Indonesian, 20221 \\ Corresponding author. Email: atikasadariah1995@gmail.com
}

\begin{abstract}
Development of an instrument based on the assessment of higher-order thinking skills in the form of an instrument that is prepared based on the needs of students of the Indonesian Language and Literature Education Study Program, Unimed. The purpose of this research is to produce an instrument based on higher order thinking skills, especially in the Receptive Skills subject that is valid, effective, and of good quality used in learning. This research is a development research ( $\mathrm{R}$ and $\mathrm{D}$ ) with a Brog and Gall development model that has been adapted to research needs. The data collection instrument used a questionnaire to analyze the needs of students and lecturers, validation of the evaluation and materials, analysis of the effectiveness of the assessment instrument through a responsive questionnaire of students and lecturers. Based on the results of the study that the results of the evaluation of the feasibility obtained from multiple choice questions were $88.75 \%$ and the assessment obtained was $87.75 \%$ with very valid criteria and deserved to be tested. Expert results on the right material and language in multiple choice obtained a score of $87.75 \%$ and an explanation of the score $84.38 \%$ has valid criteria and deserves to be tested. Based on the analysis of the effectiveness of the assessment instrument, the two achievements reached $90.27 \%$ and the ten students obtained $86.42 \%$, meaning that this assessment instrument was effective. Results Based on research on the effectiveness of the instrument for assessing higher order thinking skills in the Receptive Language Skills course in the Indonesian Language and Literature Education Study Program, it is said to be good and worthy as a learning reference
\end{abstract}

Keywords: Assessment Instruments, High Level Thinking Skills, Receptive Language.

\section{INTRODUCTION}

Seeing the importance of the demands of the IQF curriculum through the policies of the Ministry of Education and Culture through the Directorate General of the Ministry of Research and Technology, efforts are needed to develop assessments oriented towards Higher Order Thinking Skills (HOTS). Not only that, the form of the question instrument being tested must also lead to the guidance of the IQF curriculum. The Higher Education Curriculum at KKNI in the Industrial Era 4.0 leads to learning oriented towards Higher Order Thinking Skills (HOTS).

This is also based on the results of the initial observations carried out relating to the assessment and assignment system at the Medan State University College, the Indonesian Language Education Study Program has carried out the KKNI assignment system by implementing 6 tasks, namely Routine Tasks, Critical Book Review (CBR), Critical Journal Review (CJR), Idea Engineering, Mini Research, Projects and Summative tests conducted in the middle and end of the semester to measure the assessment of students' understanding of the learning material. It is known that the assessment instrument given by the lecturer team during the Mid-Semester Examination and Final Semester Examination in the form of question instruments is not oriented to HOTS questions, this can be seen from the assessment instruments compiled by lecturers quoted from the Final Semester Examination questions for Receptive Language Skills Courses such as example below: Based on what you know: a) Explain the meaning of receptive language skills from several experts! b) Explain why language skills are important? 
This is quoted based on Masniari International Journal of Research (2019:105) the Indonesian national curriculum framework (or KKNI) that began now in which program courses refer to needs analysis and future orientation [1]. Indonesia will develop an IQF curriculum that is oriented towards needs analysis. The same thing was also raised by Jati Agung (2018:2) who raised the HOTS-based assessment instrument. In accordance with the results of research conducted through his scientific work entitled "Mathematics Teacher's Interpretation of Higher Order Thinking in Bloom's Taxonomy" which explains that there are still many teaching staff, especially lecturers in this case study, are still unable to make instruments. HOTSbased questions and some students still have difficulty understanding HOTS-based materials [2].

Based on the problems above, the authors are interested in conducting research to develop an assessment instrument on Critical Reading material. Therefore, the researcher raised the title "Development of Assessment Instruments Based on Higher Order Thinking Skills in the Receptive Language Skills Course for Unimed.

\section{METHODS}

This study uses the Research and Development (R\&D) method at level IV. Sugiyono, 2017:47 Research and Development (R\&D) method at level IV which refers to the research of the Borg and Gall model to research, test, and develop existing products and are adapted based on the research model [3]. The reason researchers use the Research and Development (R\&D) method is because researchers will create new tested products, so research is needed to produce designs and development to create and test the resulting products.

\section{RESULTS AND DISCUSSION}

\subsection{Research Results}

This research is a development research, so the product of this research is a HOTS-based assessment instrument.

\subsubsection{Analyze Needs}

Before testing the feasibility of the assessment instrument to the subject matter and evaluation. The researcher first analyzed the needs of lecturers and students for the HOTS-based assessment instrument. It is known from the results of the lecturer's analysis questionnaire that $100 \%$ of the lecturers stated that they were very familiar with the assessment instrument, made their own assessment instrument, and knew the steps for preparing the instrument. $100 \%$ of the lecturers were hesitant to arrange the instrument grid before testing it out and from the students it was obtained that $80 \%$ of the students answered that learning based on higher order thinking skills (HOTS) was a new variation in learning activities and students had difficulty in answering questions based on thinking skills $(50 \%)$ regarding understanding and high level (HOTS).

\subsubsection{Test the feasibility of the Assessment instrument}

Based on the results of the study, it shows that the results of the evaluation of the feasibility of the content on the multiple-choice questions obtained a score of $88.75 \%$ and the description questions obtained a score of $87.75 \%$ with very valid criteria and deserves to be tested. The results of the material expert's assessment of the feasibility of content and language on multiplechoice questions obtained a score of $87.75 \%$ and essay questions obtained a score of $84.38 \%$ with very valid criteria and worthy of trial.

\subsubsection{Analyzing the effectiveness of the assessment instrument}

Based on the analysis of the effectiveness of the assessment instrument from two lecturers it was obtained that it reached $90.27 \%$ and for ten students it was obtained $86.42 \%$, meaning that this assessment instrument was effective. Based on the results of research on the feasibility and effectiveness of the assessment instrument based on higher order thinking skills in the Receptive Language Skills course in the Indonesian Language and Literature Education Study Program, it is said to be good and worthy of being used as a learning reference.

\subsection{Discussion}

Instrument is a tool used to collect data and gather information. One of the tools that can assist teachers in collecting data and collecting learning information is an assessment instrument. Thus the assessment instrument must describe the competencies that will be achieved by students, presented in good and interesting language. Assessment instruments can be in the form of test and non-test instruments, the instrument aims to express values and beliefs, both positive and negative.

The process of developing a HOTS-based assessment instrument in the Receptive Language Skills course in the regular class c Indonesian Language Education study program, Unimed, goes through the stages, namely; (1) Designing a HOTSbased assessment instrument grid. At this stage the researcher determines the CPMK, study of learning materials, and indicators that are adapted to those in the RPS so that an assessment instrument can be designed 
in the form of a multiple choice test of 25 questions and a description of 5 questions (2) Designing a question instrument in the form of a book containing a book cover, introduction, material summary, multiple choice questions, description questions, answer keys, bibliography, and glossary.

Tuti and Dedeh (2015: 8-14) suggested the Development of Cognitive Assessment Instruments in Chemistry Courses for Chemistry Education Students. This study aims to produce and develop cognitive assessment instruments in Chemistry courses for Chemistry students in the fourth semester [4]. This research was conducted because the quality of the assessment is still low due to the lack of educators in innovating or renewing and there are still errors in the assessment caused by making instruments that are not valid and reliable. Test the feasibility of the assessment instrument and the display quality of the instrument using a 4D model, but only at the develop stage. The results of the research on the development of cognitive assessment instruments have a valid validation level and a reliability value of 0.758 . Similar to this study, the development of assessment instruments was carried out by researchers due to the lack of implementation of HOTS-based instruments by lecturers and students' low understanding of HOTS-based materials and questions. The research carried out by Tuti and Dedeh uses a 4D model, while this study uses the Borg and Gall R \& D development model method.

\section{CONCLUSION}

The process of developing a HOTS-based assessment instrument in the Receptive Language Skills course in the regular class c Indonesian Language Education study program, Unimed, goes through the stages, namely; (1) Designing a HOTSbased assessment instrument grid. At this stage the researcher determines the CPMK, study of learning materials, and indicators that are adapted to those in the RPS so that an assessment instrument can be designed in the form of a multiple choice test of 25 questions and a description of 5 questions (2) Designing a question instrument in the form of a book containing a book cover, introduction, material summary, multiple choice questions, description questions, answer keys, bibliography, and glossary.

The results of the research obtained in this thesis that the feasibility of the assessment instrument as a result of the evaluation of the feasibility of the content on the multiple choice questions obtained a score of $88.75 \%$ and the description of the questions obtained a score of $87.75 \%$ with very valid criteria and deserves to be tested. The results of the material expert's assessment of the feasibility of content and language on multiple-choice questions obtained a score of $87.75 \%$ and essay questions obtained a score of $84.38 \%$ with very valid criteria and worthy of trial. Based on the analysis of the effectiveness of the assessment instrument from two lecturers it was obtained that it reached $90.27 \%$ and for ten students it was obtained $86.42 \%$, meaning that this assessment instrument was effective.

\section{REFERENCES}

[1] Masniari, Surya, Tracer Study as the Medium of Developing Teaching Materials. 2019, https://www.ijrrjournal.com/IJJR_vol 6_issue_11_nov2019.

[2] Agung, Jati, International Journal of Mathematics: Mathematics Teacher's Interpretation of Higher Order Thinking in Bloom's Taxonom, 2018, www. Iejme.com.volume 3 issue 2 pp 96-109.

[3] Sugiyono, Educational Research Methods Quantitative, Qualitative, and R\&D Approaches, 2010, Bandung: Alfabeta.

[4] Kurniati, Tuti dan Kurniasih, Dedeh, Journal: Development of Cognitive Assessment Instruments in School Chemistry Courses for Chemistry Education Students, University. 